\title{
Otterboard hydrodynamic performance testing in flume tank and wind tunnel facilities
}

\author{
Fernando Mellibovsky ${ }^{\mathrm{a}, *}$, Joana Prat ${ }^{\mathrm{b}}$, Emilio Notti ${ }^{\mathrm{c}}$, Antonello Sala ${ }^{\mathrm{c}}$ \\ ${ }^{a}$ Aerospace Engineering Division - Physics Dept., Universitat Politècnica de Catalunya, \\ 08034, Barcelona \\ ${ }^{b}$ EPSEVG-SARTI, Mathematics Dept., Universitat Politècnica de Catalunya, 08800, \\ Vilanova i la Geltrú \\ ${ }^{c}$ National Research Council (CNR), Institute of Marine Sciences (ISMAR), 60125,
} Ancona, Italy

\begin{abstract}
Two pelagic otterboards, previously tested in a wind tunnel, have been tested in a flume tank prior to their analysis in real working conditions in sea trials. This intermediate step aims at providing guidance for sea trial planning and a basis for otter board performance analysis from real campaign data. The doors were rigged in working-like conditions in the flume tank, with onboardmounted attitude sensors to provide at the same time a noisy environment as expected in sea trials and accurate measurement of all quantities relevant to precise determination of hydrodynamic angles and forces. The trends found in flume tank experiments closely match wind tunnel results, although systematic offset has been observed that can be ascribed to deviations between nominal and real water velocity, due to inhomogeneous veloctiy distribution in the cross-section.
\end{abstract}

Keywords: wind tunnel, flume tank, otter board, hydrodynamics

\section{Introduction}

The effective and efficient use of a trawl gear, be it bottom, pelagic or semipelagic, relies on the adequate choice, sizing and rigging of one of its

\footnotetext{
${ }^{*}$ Corresponding author. email: fernando.mellibovsky@upc.edu

Email addresses: fernando.mellibovsky@upc.edu (Fernando Mellibovsky), joana@ma4.upc.edu (Joana Prat), e.notti@an.ismar.cnr.it (Emilio Notti), a.sala@ismar.cnr.it (Antonello Sala)
} 
key components: trawl doors [1, 2]. In ordinary trawling, these under water devices, also known as otter boards, fulfill the crucial task of ensuring a suitable horizontal net opening, and this is to be achieved with minimum drag for optimal trawler fuel consumption [3, 4, 5]. They are also responsible for keeping the right net depth in pelagic trawling and must be designed for minimal sea bottom disruption in case of bottom trawling. Stable handling of the full gear must also be guaranteed while manoeuvering, deploying and stowing [6].

There exist a wide range of numerical models that simulate net dynamics [7, 8, 9, 10, 11, 12, 13], and a few extend to include complete gears, exploiting a sometimes crude [14], sometimes fair [15, 16] description of trawl door behaviour. The only full trawl gear simulation to date embodying a complete and detailed modelling of the otter boards was undertaken by [17].

Traditional flume tank tests provide drag and lift coefficients as a function of the yaw orientation angle of the door (notice that the terminology usually employed -angle of attack- is a misnomer in this context) in allegedly no-heel and no-pitch conditions [18, 19]. The coefficients are usually obtained via reduced-scale tests that not always preserve dynamic similarity [20, 21]. Although this procedure might suffice to the needs of the trawl fishing industry, it has shortcomings that render it inappropriate for the detailed analysis of otterboard performance and the intimate understanding of its behaviour in real conditions that is crucial to optimising both design and rigging as well as off-design operation. Preventing stability issues in non-standard realisitc conditions or exploiting control systems to dynamically pilot the full gear require an accurate modelling of the hydrodynamic forces acting on the trawl doors along with the rest of gear components and their interactions [22, 17]. It is therefore essential that moments and forces in all three axes can be predicted for any possible attitude of the door, as given by its two hydrodynamic angles (angle of attack and sideslip). Dynamical effects derived from acceleration or rotation in the three axes also play a role, but accurately assessing their influence is beyond the scope of the test methods here presented.

Clever exploitation of traditional flume tank facilities, using door-mounted sensors, has allowed a more detailed analysis of bottom otter board performance [23]. In these experiments, both heel and pitch angles were set to prescribed values. The inclusion of load cell sensors on the shoe allowed measurement of the bottom normal reaction thus providing a means of calculating all three force components alongside quantitative assessment of potential seabed impact [23]. 
Modern flume tank facilities (SINTEF Fisheries, Hirtshals) have improved on traditional techniques by suspending the otter board from a 6-component balance (three-axes force and moment measurement) that can accurate orient the model in any desired attitude. The downside is their operation cost, as compared with general-purpose wind tunnel testing, which has been seldom used in analysing trawl door hydrodynamics [24, 25], despite a number of evident advantages.

Numerical modelling with Computational Fluid Dynamics tools is a powerful alternative that can potentailly provide hydrodynamic coefficients in all detail, but its computational cost makes it still inadequate for large parametric studies and, due to the complex unsteady hydrodynamics at the operating flow regimes at which otter boards work, which require turbulence modelling, experimental validation is unavoidable [26, 27, 28].

Otter board hydrodynamics are extremely difficult to test at sea in fullscale experiments and very few studies have attempted at measuring attitude and forces in real operation [23]. It is however of the utmost importance to understand trawl door behaviour in real operating conditions to relate back to more controlled wind tunnel or flume tank experiments.

The most comprehensive otter board measurements at sea 23 up to date assimilate trawler velocity to door velocity, which is a reasonable approximation in steady trawling in the absence of depth-dependent sea currents. Forces acting on the otter board are inferred from accurate tension measurements on warp and bridles close to their attachment points on the door (just upstream and downstream), door spread and depth and cable deployment lengths, yet with crude cable bending assumptions in determining force orientation. Otter board pitch and roll angles are measured with an accelerometer-based attitude sensor, leaving yaw as the only unknown orientation angle. This alone prevents reliable assessment of the operating hydrodynamic angles, which is fundamental to estimating the expected hydrodynamic forces for comparison with measurements.

The main objective of the present study is to exploit traditional flume tank tests as an intermediate step to carrying fully controlled tests in wind tunnels or modern flume tanks to realistic operating conditions at sea. The aim here is therefore to bridge the gap between precise experiments (wind tunnel and modern flume tank facilities) and the uncertainties faced in actual operation (sea trials) by realistically rigging the otterboard in an environment in which sufficiently accurate measurement is still feasible (traditional flume tanks with door-mounted attitude sensors). While wind tunnel and modern 
flume tank experiments constitute a reference for accuracy, traditional flume tank tests are still useful to realistically reproduce sea conditions by mimicking actual rigging, and results can be cross-checked against wind tunnel and modern flume tank results.

One aim is therefore to assess the capability of traditional flume tank facilities to conduct the kind of parametric studies that are feasible in modern flume tanks and wind tunnels, relinquishing the precise variation of the hydrodynamic angles but retaining a somewhat accurate measurement of door orientation and the resulting forces.

An accessory goal is then to validate the use of attitude probes, based on accelerometers for pitch and roll and on a magnetic compass for yaw (or a gyro-based inertial reference system), for their use in sea trials. Again, a traditional flume tank provides the adequate framework for validation, as force measurement and projection is accurate enough while the rigging method provides a sufficiently noisy environment to test measurement stability of the orientation probe in realistic conditions. Balances used in wind tunnels and modern flume tanks are too stable for being representative of the noisy conditions the probes will experience in sea trials.

Wind tunnel and traditional flume tank tests of two models of pelagic otter boards will be compared in order to provide insight as to the way fullscale sea trials must be undertaken.

The paper is then structured as follows: wind tunnel and flume tank tests are described in $\$ 2$. Test results for two production otter boards are presented in \$3 and comparison between flume tank and wind tunnel results discussed in $\$ 4$. Finally, in $\$ 5$ we summarise the main results and briefly analyse their relevance to full scale sea trials.

\section{Methods}

Two models of flying (pelagic) trawl doors, Thyborøn type 15 vf and Grilli Fly, have been tested in both wind tunnel and flume tank facilities for comparison11The geometric parameters of the models, which are made of the same materials as real scale doors (steel) for their suitability for sea trials, are given in table 1. Reference for roll is taken with the span-line (tip-to-tip) in the upright position, such that the body $z$-axis runs parallel to the spanline. Note that the relevant parameter to unambiguously set a reference for roll is $\phi^{e}$, defined as the angle between the tip-to-tip span line and the earth vertical when the door is standing flat on its shoe. The effects of the upper 
and lower panel dimensions and respective dihedral angles on the definition of the roll reference are all encompassed by this single parameter. For details on how to relate the geometric parameters of the trawl door to $\phi^{e}$, see figure 1 in [25].

Wind tunnel experiments were done at the MariKom wind tunnel facilities (http://www.marikom.uni-rostock.de/en/), located at Rostock University campus in Germany. The wind tunnel is of the Göttingen construction type (also known as Prandtl type or closed return wind tunnel) with an open test chamber of square cross-section of $1.4 \mathrm{~m}$ side and provides an accurate three-axes positioning system and a six-component balance for forces and moments measurement. Tests were conducted on 20 October 2013, and a detailed account of the data analysis procedure and results for the Thyborøn type $15 \mathrm{vf}$ is available at [25].

Flume tank tests were conducted on 10 September 2014 at the Marine Institute in St John's, Newfoundland, Canada. The flume tank has a test section of $8 \mathrm{~m} \times 4 \mathrm{~m} \times 22.25 \mathrm{~m}$ width, depth and length, respectively (https: //www.mi.mun.ca/facilities/flumetank/).

Three pumps or impellers located in the return section circulate the water around the tank. Each impeller or pump is driven by a $125 \mathrm{hp}$ DC motor. The tank is fitted with flow straighteners in the lower section last turn to remove swirl. Downstream from the guide vanes, the flow crosses a honeycomb grid to make the flow as uniform as possible across the test chamber cross-section. The tank is calibrated for mean velocity, as averaged across 200 equispaced individual measurements on a grid covering the full cross-sectional area of the chamber. Mean velocity is correlated with pump rotational speed (rpm), such that flume tank nominal speed during experiments is inferred from pump speed. Individual pumps are regularly calibrated for accuracy and repeatability, but actual average speed in the test section is checked less frequently and no guarantee is provided of uniform velocity distribution in the cross-section. The maximum nominal speed of the flume tank is slightly short of $1 \mathrm{~m} / \mathrm{s}$.

Doors were weighted in air $\left(W_{a}\right)$ and in water $\left(W_{w}\right)$ and rigged within the flume tank as in real working conditions for the tests, pulled by the warp at the front and by two lines connected to the bridle at the back. The flume tank was operated at a constant nominal water speed $V$, set to $0.7 \mathrm{~m} / \mathrm{s}$ for the Grilly door and to $0.95 \mathrm{~m} / \mathrm{s}$ for the Thyboron door, corresponding to chord-based Reynolds number $R e \simeq 2.3 \times 10^{5}$ in both cases (water density and viscosity estimated at $\rho \simeq 10^{3} \mathrm{~kg} / \mathrm{m}^{3}$ and $\nu \simeq 1.2 \times 10^{-} 6 \mathrm{~m}^{2} / \mathrm{s}$ for $T \simeq 15^{\circ} \mathrm{C}$ ). 
Warp $\left(T_{w}\right)$ and bridle $\left(T_{b}\right)$ tensions were measured at their respective ends and their attitude geometrically measured from top $\left(\psi_{w}^{t}\right.$ and $\left.\psi_{b}^{t}\right)$ and side views $\left(\psi_{w}^{s}\right.$ and $\left.\psi_{b}^{s}\right)$ as shown in Fig. 2 a and 2 c. The yaw angle $(\psi)$ of the door was measured from a top view as shown in Fig. $2 \mathrm{p}$, while pitch $(\theta)$ and roll $(\phi)$ were recovered from an accelerometer-based attitude sensor mounted on the trawl door.

The usual attitude angles of warp and bridle are reconstructed from the top and side view projections:

$$
\tan \theta_{w, b}=\sqrt{\tan ^{2} \psi_{w, b}^{s}+\tan ^{2} \psi_{w, b}^{t}}, \quad \tan \phi_{w, b}=\frac{\tan \psi_{w, b}^{t}}{\tan \psi_{w, b}^{s}} .
$$

Note that the attitude angles are inferred from geometrical measurements in a slightly more subtle way than usual practice of straightforward parallel projection for better accuracy, although discrepancies are negligible.

Warp and bridle forces are then expressed in flume tank reference frame (Earth frame of [25]) by projecting measured tensions according to attitude angles:

$$
\begin{aligned}
F_{x}^{w, b} & =T_{w, b} \cos \theta_{w, b} \\
F_{y}^{w, b} & =T_{w, b} \sin \theta_{w, b} \sin \phi_{w, b} \\
F_{z}^{w, b} & =T_{w, b} \sin \theta_{w, b} \cos \phi_{w, b} .
\end{aligned}
$$

The hydrodynamic forces in flume tank frame are then assessed by equilibrating warp, bridle and weight forces:

$$
\begin{aligned}
& F_{x}=-\left(F_{x}^{w}-F_{x}^{b}\right) \\
& F_{y}=-\left(-F_{y}^{w}-F_{y}^{b}\right) \\
& F_{z}=-\left(-F_{z}^{w}-F_{z}^{b}+W_{w}\right) .
\end{aligned}
$$

Forces are non-dimensionalised with water density $\left(\rho_{w}\right)$, trawl door projected area $(S)$ and free-stream water velocity to produce force coefficients:

$$
C_{x, y, z}=\frac{F_{x, y, z}}{\frac{1}{2} \rho_{w} S V^{2}}
$$


The hydrodynamic angles of the trawl door are the angle of attack $(\alpha)$ and sideslip angle $(\beta)$, which measure the orientation of the door with respect to its velocity. These are obtained from measured attitude angles by first expressing the velocity axis ( $\mathrm{x}$-axis in the flume tank frame) in body coordinates [25]

$$
\hat{\mathbf{x}} \equiv \hat{\mathbf{x}}_{\mathrm{ft}}^{b}=c_{\psi} c_{\theta} \mathbf{i}+\left(c_{\psi} s_{\theta} s_{\phi}-s_{\psi} c_{\phi}\right) \mathbf{j}+\left(c_{\psi} s_{\theta} c_{\phi}+s_{\psi} s_{\phi}\right) \mathbf{k},
$$

where $c_{x}$ and $s_{x}$ denote cosine and sine, respectively, of the angle indicated by the subscript $x$, and then computing the orientation angles with respect to $\hat{\mathbf{x}}$ using

$$
\tan \alpha=\frac{-\hat{\mathbf{x}} \cdot \mathbf{j}}{\hat{\mathbf{x}} \cdot \mathbf{i}}, \quad \tan \beta=-\frac{-\hat{\mathbf{x}} \cdot \mathbf{k}}{(\hat{\mathbf{x}} \cdot \mathbf{i}) c_{\alpha}-(\hat{\mathbf{x}} \cdot \mathbf{j}) s_{\alpha}} .
$$

These angles are finally used to project force coefficients in the hydrodynamic reference frame for further comparison with wind tunnel results:

$$
\left(\begin{array}{c}
C_{D} \\
C_{L} \\
C_{S}
\end{array}\right)=\left(\begin{array}{ccc}
c_{\alpha} c_{\beta} & -s_{\alpha} c_{\beta} & s_{\beta} \\
s_{\alpha} & c_{\alpha} & 0 \\
-c_{\alpha} s_{\beta} & s_{\alpha} s_{\beta} & c_{\beta}
\end{array}\right)\left(\begin{array}{c}
C_{x} \\
C_{y} \\
C_{z}
\end{array}\right) .
$$

The standard deviation of pitch and roll angles as measured by the attitude sensor remains within $1^{\circ}$ for all experimental points. This accounts for an uncertainty of under $\pm 0.5^{\circ}$ and $\pm 1.5^{\circ}$ in determining the angle of attack and sideslip, respectively. No significant hydrodynamic force deviations are to be expected from this level of uncertainty according to previous wind tunnel results [25].

\section{Results}

Fig. 3 shows flume tank results for the Thyboron vf 15 otter board. Indicated with plus signs in the bottom panel are the lift $\left(C_{L}\right.$, black $)$, drag $\left(C_{D}\right.$, blue) and side $\left(C_{S}\right.$, magenta) force coefficients, duely reported in Table 2 . alongside the actual hydrodynamic angles (attack $\alpha$ and sideslip $\beta$ ) at each specific experimental point. The usual increasing, almost linear, trend of $C_{L}$ with increasing $\alpha$ is observed, with a little scatter derived from small variations of $\beta \in[-5,5]^{\circ}$. $C_{D}$ also follows an increasing trend, compatible with a parabolic drag polar, while $C_{S}$ are small and scattered around 0 due to the small $|\beta|$ for all experimental points. 
Wind tunnel predictions for the exact experimental hydrodynamic angles measured in the flume tank have been calculated by interpolation from wind tunnel results at the MariKom wind tunnel facilities in Rostock [25]. The interpolated predictions are given in Table 2 and marked with circles in the bottom panel of fig. 3. Flume tank trends closely mimick the trends anticipated by wind tunnel results, but both $C_{L}$ and $C_{D}$ are systematically underestimated. It is however remarkable how the fine trend associated to small $\beta$-variations is compatible between flume tank and wind-tunnel results. In order to discard that inaccuracies in the measurement of the sideslip angle are responsible for the offset, wind tunnel predictions for $\beta=\{-5,0,5\}^{\circ}$ have been obtained and plotted as dashed lines. As expected, the effects are negligible for the small sideslip angles considered, so that the origin for deviations has to be sought elsewhere. The top panel of Fig. 3 shows the relative discrepancy, defined as $\varepsilon_{C_{x}}=\left(C_{x}^{w t}-C_{x}^{f t}\right) / C_{x}^{w t}$, in the lift (black trianglesdown) and drag (blue triangles-up) coefficients. Both relative differences are consistently around $20 \% \sim 30 \%$, with drag tending to have higher deviations than lift at the high- $\alpha$ end.

Results for the Grilli Fly otter board are listed in Table 3 and shown in Fig. 4. $C_{L}$ grows linearly with $\alpha$ until stall, where it starts decreasing. $C_{D}$ consistently grows across the full range of $\alpha$ explored. The same observations made for the Thyboron regarding trend comparison against wind tunnel apply to the Grilly model for $\alpha<25^{\circ}$. For $\alpha>25^{\circ}$, not only the trends, but also the values seem to match wind tunnel results. The relative discrepancies are around $15 \%$ for lift and $20 \%$ for drag at the low $\alpha$ range and drop below $10 \%$ at the highest angles of attack.

\section{Discussion}

Flume tank results feature a systematic deviation in both $C_{L}$ and $C_{D}$, with a tendency to under estimate wind tunnel data. The relative deviation remains reasonably stable across the full range of $\alpha$ for the Thyboron and also within the low and high $\alpha$-ranges for the Grilli door. The discrpancy levels are highest for the Thyboron $(20 \sim 30 \%)$, a little lower for the Grilli at low- $\alpha(15 \sim 20 \%)$ and much lower at high- $\alpha(<10 \%)$.

Intriguingly, the lift coefficient deviation for the Thyboron otter board goes in the exact opposite direction than previous comparison of wind tunnel data with published results obtained at Hirtshals flume tank facilities in Denmark (http://www.thyboron-trawldoor.dk). While present $C_{L}$ results are 
systematically below wind tunnel predictions, the experiments at Hirtshals resulted in higher values. Besides the poor control on hydrodynamic angles in old flume tank tests, the discrepancies where then ascribed to the possibility that wind tunnel results could have been done in subcritical conditions due to low pre-turbulence levels into the test section, despite adquately preserving Reynolds similarity [25, 29]. In present flume tank results, however, the hydrodynamic angles have been duely measured and Reynolds number and pre-turbulence levels guarantee the supercritical regime, such that the underestimation of force coefficients must have a different origin.

The persistency of the deviation level for large ranges of $\alpha$ are suggestive of a unique source of error, that must be slightly different for the Thyboron and Grilli Fly doors, as well as for the low- and high- $\alpha$ regimes of the latter. Load gauges are frequently and accurately calibrated in the flume tank, and angles are measured graphically from pictures, such that they can be cross-checked. Veloctiy calibration is however undertaken more rarely by correlating average velocity across flume tank cross-section with driving-pump rotation speed. The average velocity is calculated from independent readings of $20 \times 10$ velocity probes fitted on a grid that spans the full cross-sectional area of the flume tank $(8 \mathrm{~m} \times 4 \mathrm{~m})$. No gaurantee is given that speed is constant across the cross-section, such that different velocities might occur in different locations. Test position of trawl doors is kept as constant as possible precisely to preserve velocity among different test conditions, but deviations from nominal speed might be occurring in a systematic way. The net effect of a velocity error is homogeneous on all coefficients regardless of door attitude:

$$
C_{x}^{\text {real }}=\frac{F_{x}}{\frac{1}{2} \rho S V_{\text {real }}^{2}}=\frac{F_{x}}{\frac{1}{2} \rho S V_{\text {nom }}^{2}}\left(\frac{V_{\text {nom }}}{V_{\text {real }}}\right)^{2}=C_{x}^{\text {nom }}\left(\varepsilon_{V}-1\right)^{2},
$$

such that the error on force coefficients is directly related with the error in velocity by

$$
\varepsilon_{C_{x}}=\frac{C_{x}^{\text {real }}-C_{x}^{\text {nom }}}{C_{x}^{\text {real }}}=1-\frac{1}{\left(1-\varepsilon_{V}\right)^{2}}=-2 \varepsilon_{V}-3 \varepsilon_{V}^{2}+O\left(\varepsilon_{V}^{3}\right) .
$$

To first order, a small overestimation of flume tank velocity results in an underestimation of the force coefficient by double that amount.

A velocity error $\varepsilon_{V} \simeq 11 \%$ would satisfactorily explain both $C_{L}$ and $C_{D}$ deviations for the Thyboron across the full $\alpha$-range. A smaller velocity error $\varepsilon_{V} \simeq 8 \%$ resolves deviations for the Grilli fly at the low $\alpha$-range. Different 
corrections can be explained from the fact that the flume tank was operated at different nominal velocities for the Thyboron and Grilli fly doors. The higher velocity $V_{\text {nom }}=0.95 \mathrm{~m} / \mathrm{s}$ (full throttle) used for the Thyboron is understandingly proner to incur larger error than the more modest $V_{\text {nom }}=$ $0.7 \mathrm{~m} / \mathrm{s}$ used for the Grilli. Applying the same correction to the high $\alpha$-range on the flume tank Grilli results makes both $C_{D}$ and $C_{L}$ overshoot wind tunnel predictions. This is again compatible with supercriticality retarding stall in the flume tank with respect to wind tunnel conditions.

Other potential sources of uncertainty, such as cable warpage or buoyancy and hydrodynamic forces, have been assessed as negligible in comparison with door hydrodynamic forces.

The discrepancies with respect to Hirtshals data might be explained as the concatenation of the two sources discussed -velocity inaccuracy and regime change-, provided that tests at St. John's were done in subcritical conditions. This would require that preturbulence levels were sufficiently low, which cannot be assessed from available data. Otherwise, the back-to-back comparison would be suggestive that some additional (unknown) source of discrepancy must be at work. However, it must be kept in mind that Hirtshals data is incomplete in the sense that zero roll and pitch had to be assumed in order to allow comparison against wind tunnel results. Any attempt at relating to Hirtshals results is thwarted by the degree of uncertainty introduced by these assumptions and other flaws in the testing procedure that were thoroughly discussed elsewhere [25].

\section{Conclusions}

Two pelagic otter boards have been tested in a traditional flume tank by realistic rigging in working-like conditions and orientation angles have been measured with an accelerometer-based attitude probe. Attitude measurement, together with an improved orthogonal-projection method of measured tensions in the flume tank, have been employed to allow for comparison with previous wind tunnel results. This comparison has shown good agreement in hydrodynamic force coefficients trends although a systematic offset has been observed that can be ascribed to deviations between actual and nominal water speed. The strong dependence of coefficients on flow speed, noticeable even in controlled experiments in a flume tank, make it all the more important to accurately assess door speed during campaign. To this end, it might be advisable to directly measure door speed with pitot-tube technol- 
ogy instead of assuming an hydrodynamic speed equal to ship velocity or even GPS-based velocimetry.

The reasonably good match in the fine trends of coefficients with hydrodynamic angles gives confidence that the attitude sensor can be carried to sea trials and provide valuable information on door orientation. A reliable measurement of the door yaw angle remains as the last challenge, along with an accurate model of cable deformation, to provide a full description of otter board performance in real trawling.

Although the flume tank tests reported herein have allowed for the validation of attitude probes in conditions that are closer to sea trials, wind tunnel tests remain, to the authors opinion, the best choice for extensive exploration of the hydrodynamic performances of otter boards. Special care must nonetheless be taken in preserving Reynolds similarity and matching realistic pre-turbulence levels with turbulence-generator grids upstream from the test section. The tight control on door attitude and incoming velocity, combined with high measurement accuracy and low exploitation costs, bestow wind tunnels with a great potential for otter board testing.

\section{Acknowledgments}

We kindly thank George Legge, Paul Winger, Harold Delouche and Tara Perry for their assistance in setting up and running the flume tank tests at the Marine Institute in St. John's, Newfoundland, Canada, and for valuable discussions on the results.

We would also like to renew our thanks to Mathias Paschen, Sebastian Schreier and Christian Semlow (MariKom GmbH) for their help in setting up and carrying out the wind tunnel experiments at their facilities in Universität Rostock.

This work was partially funded by the EC Commission through the Seventh Framework Programme with the Research project BENTHIS (Benthic ecosystem fisheries impact study, KBBE 2012.1.2-09, Grant Agreement Nr. 312088) and the Flagship Project RITMARE "The Italian Research for the Sea", coordinated by the Italian National Research Council and funded by the Italian Ministry of Education.

The research of Fernando Mellibovsky (Serra-Húnter fellow) and Joana Prat was also supported by the Spanish Ministry of Economy and Competitivity under grants CGL2011-28682-C02-02 and FIS2016-77849-R. 
[1] M. Paschen, Prediction of the dynamic behaviour of pelagic trawl doors, in: C.-W. Lee (Ed.), Contributions on the Theory of Fishing Gears and Related Marine Systems Vol. 4, 2006, pp. 11-26.

[2] E. Notti, F. De Carlo, J. Brčić, A. Sala, Technical specifications of mediterranean trawl gears, in: M. Paschen (Ed.), Contributions on the Theory of Fishing Gears and Related Marine Systems Vol. 8. Proceedings of the 11th International Workshop on methods for the development and evaluation of maritime technologies (Rostock, 9-12 October 2013), 2013, pp. 163-169.

[3] A. Sala, A. Lucchetti, V. Palumbo, K. Hansen, Energy saving trawl in mediterranean demersal fisheries, in: G. Soares, Kolev (Eds.), Ocean Engineering and Coastal Resources, Taylor \& Francis Group, London, 2007, pp. 961-964.

[4] G. Buglioni, E. Notti, A. Sala, E-audit: Energy use in italian fishing vessels, in: Rizzuto, G. Soares (Eds.), Sustainable maritime transportation and exploitation of sea resources, Taylor \& Francis Group, London, 2012 .

[5] E. Notti, A. Sala, Propulsion system improvement for trawlers, in: G. Soares, L. Pea (Eds.), Developments in Maritime Transportation and Exploitation of Sea Resources. Proceedings of the 15th International Congress of the International Maritime Association of the Mediterranean (La Corua, 14-17 October 2013), 2013, pp. 1085-1090.

[6] FAO, Otter board design and performance. In: Fishing Manuals, FAO, Rome, 1974.

[7] J. Bessonneau, D. Marichal, Study of the dynamics of submerged supple nets (applications to trawls), Ocean Engineering 7 (1998) 563-583.

[8] G. Niedzwiedz, M. Hopp, Rope and net calculations applied to problems in marine engineering and fisheries research, Arch. Fish. Mar. Res. 46 (1998) 125-138.

[9] F. O'Neill, Axisymmetric trawl cod-ends made from netting of a generalized mesh shape, IMA Journal of Applied Mathematics 62 (1999) $245-262$. 
[10] R. Wan, F. Hu, T. Tokai, A static analysis of the tension and configuration of submerged plane nets, Fisheries Science 68 (2002) 815-823.

[11] D. Priour, Analysis of nets with hexagonal mesh using triangular elements, International Journal Numerical Methods in engineering 56 (2003) 1721-1733.

[12] K. Suzuki, T. Takagi, T. Shimizu, T. Hiraishi, K. Yamamoto, K. Nashimoto, Validity and visualization of a numerical model used to determine dynamic configurations of fishing nets, Fisheries Science 69 (2003) 695-705.

[13] C. Lee, J. Lee, B. Cha, H. Kim, J. Lee, Physical modeling for underwater flexible systems dynamic simulation, Ocean Engineering 32 (2005) 331347.

[14] C. Lee, J. Lee, Modeling of a midwater trawl system with respect to the vertical movements, Fisheries Science 66 (2000) 851-857.

[15] A. Folch, J. Prat, J. Antonijoan, A. Manuel, A. Sala, F. Sard, Simulation of bottom trawl fishing gears. A simplified physical model, in: C. G. Soares, P. Kolev (Eds.), Maritime Industry, Ocean Engineering and Coastal Resources, Taylor and Francis Group, 2007, pp. 921-927.

[16] J. Prat, J. Antonijuan, A. Folch, A. Sala, A. Lucchetti, F. Sard, A. Manuel, A simplified model of the interaction of the trawl warps, the otterboards and netting drag, Fisheries Research 94 (2008) 109-117.

[17] K.-J. Reite, PhD:Modeling and control of trawl systems, Norwegian University of Science and Technology, Trondheim, 2006.

[18] S. F. I. Authority, IFREMER, DIFTA, Otterboard performance and behaviour, Comission of the European Communities FAR, 1993.

[19] A. Strickland, Guidelinea for the construction and rigging of common steel vee doors, The Seafish Industry Authory, 1995.

[20] C. . Park, K. Matuda, F. Hu, Effects of dihedral and sweepback angles on lift and drag of the cambered otter board, Nippon Suisan Gakkaishi 62 (1996) 920-927. 
[21] K. Fukuda, F. Hu, T. Tokai, K. Matuda, Effects of aspect and camber ratios on hydrodynamic characteristics of biplane-type otter board, Nippon Suisan Gakkaishi 65 (1999) 860-865.

[22] M. Paschen, PhD: Beitrag zur Voraussage von Bewegungsbahnen pelagischer Schleppnetze nach Einleitung von Schiffsmanövern, University of Rostock, Rostock, 1981.

[23] A. Sala, J. Prat, J. Antonijuan, A. Lucchetti, Performance and impact on the seabed of an existing and an experimental otterboard: comparison between model testing and full-scale sea trials, Fisheries Research 100 (2009) 156-166.

[24] K.-J. Reite, A. Sorensen, Mathematical modeling of the hydrodynamic forces on a trawl door, Journal of Ocean Engineering 31 (2006) 432-453.

[25] F. Mellibovsky, E. Notti, J. Prat, A. Sala, Testing otter board hydrodynamic performances in wind tunnel facilities, Ocean Engineering 104 (2015) 52-62.

[26] B. Vincent, D. Marichal, Modelling the dynamics of trawl doors in a trawl gear, in: C.-W. Lee (Ed.), Contributions on the Theory of Fishing Gears and Related Marine Systems Vol. 4, 2006, pp. 71-79.

[27] E. Jonsson, Aerodynamic optimization by variable-resolution modeling and space mapping, Reykjavik University, Reykjavik, 2012.

[28] Y. Takahashi, Y. Fujimori, F. Hu, X. Shen, N. Kimura, Hydro-Dynamic characteristics of the otterboard by CFD approach, Contributions on the Theory of Fishing Gears and Related Marine Systems Vol. 8. Paschen, M., 2013.

[29] F. Mellibovsky, E. Notti, J. Prat, A. Sala, Assessment of hydrodynamic performance and impact of otterboards in wind tunnel trials, in: Proceedings of the International ICES Symposium on Effects of fishing on benthic fauna, habitat and ecosystem function (16-19/06/2014, Troms $\varnothing$, Norway), 2014, p. 82. 
a)

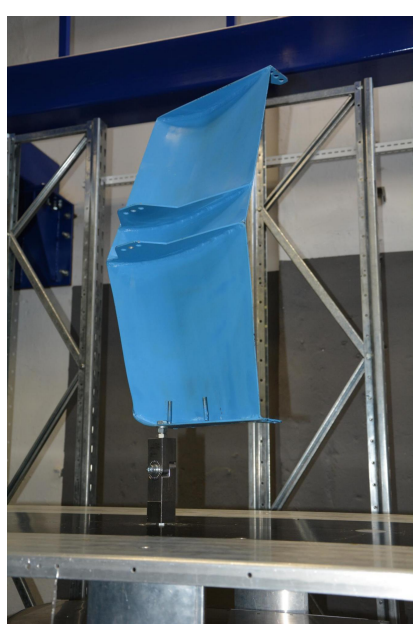

b)

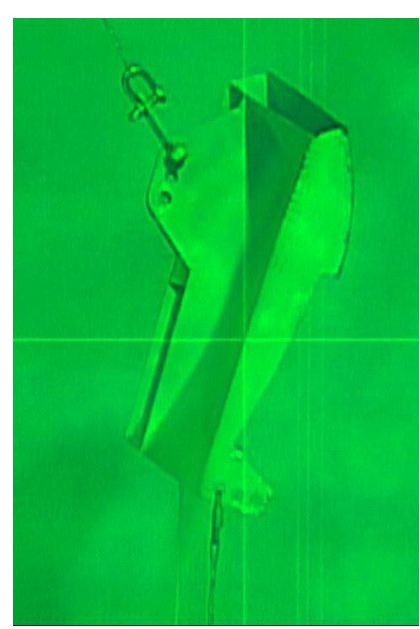

Figure 1: GrilliFly otterboard during (a) wind tunnel, and (b) flume tank tests.

\begin{tabular}{cccc}
\hline symbol & Thyboron vf 15 & Grilli Fly & units \\
\hline$l$ & 0.320 & 0.374 & $\mathrm{~m}$ \\
$b$ & 0.790 & 0.714 & $\mathrm{~m}$ \\
$S$ & 0.260 & 0.267 & $\mathrm{~m}^{2}$ \\
$A R$ & 2.50 & 1.91 & - \\
$W_{\text {air }} / g$ & 8.90 & 9.36 & $\mathrm{~kg}$ \\
$W_{\text {water }} / g$ & 7.43 & 8.12 & $\mathrm{~kg}$ \\
$\phi^{e}$ & 8.50 & 1.75 & $\circ$
\end{tabular}

Table 1: Geometric parameters of the models. A graphical interpretation can be found in figure 1 of 25. Mean chord $l$, span $b$, area $S=b l$, aspect ratio $A R=b^{2} / S=b / l$, weight in air $W_{\text {air }}$ and weight in water $W_{\text {water }}$. Gravity accleration is $g=9.81 \mathrm{~m} / \mathrm{s}^{2}$. $\phi^{e}$ is the angle between the tip-to-tip span line and the earth vertical when the door is standing flat on its shoe. 
a)

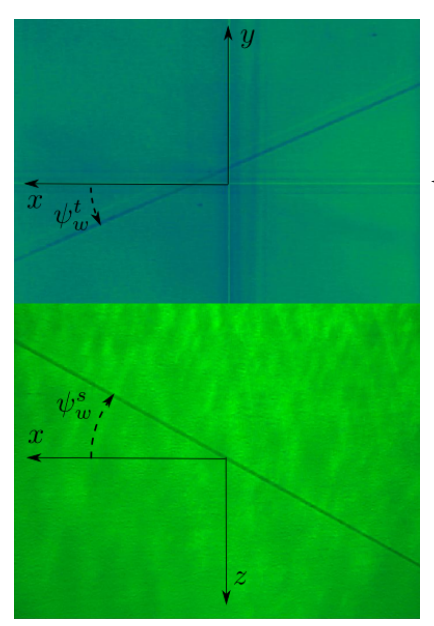

b)

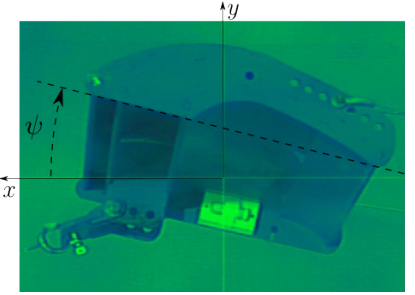

c)

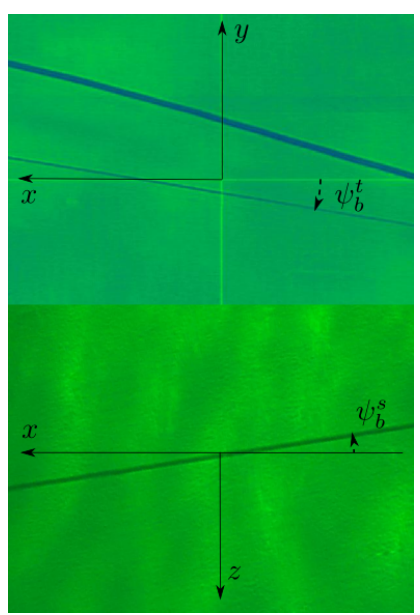

Figure 2: Top and side view of (a) warp, (b) door and (c) bridle, with attitude angle definition. The angles, in flume tank reference frame, are measured graphically from pictures as shown.

\begin{tabular}{|rr|rcc|ccc|rcr|}
\cline { 3 - 11 } \multicolumn{1}{l|}{} & \multicolumn{3}{c|}{$C_{D}$} & \multicolumn{3}{c|}{$C_{L}$} & \multicolumn{3}{c|}{$C_{S}$} \\
\hline$\alpha$ & \multicolumn{1}{c|}{$\mathrm{FT}$} & $\mathrm{WT}$ & $\varepsilon_{C_{D}}$ & $\mathrm{FT}$ & $\mathrm{WT}$ & $\varepsilon_{C_{L}}$ & $\mathrm{FT}$ & $\mathrm{WT}$ & $\varepsilon_{C_{S}}$ \\
\hline 13.6 & 2.69 & 0.293 & 0.316 & 0.07 & 0.87 & 1.10 & 0.21 & 0.061 & 0.056 & -0.10 \\
16.5 & 2.58 & 0.273 & 0.361 & 0.24 & 0.98 & 1.27 & 0.23 & 0.118 & 0.068 & -0.73 \\
16.9 & 1.69 & 0.303 & 0.369 & 0.18 & 0.94 & 1.30 & 0.28 & 0.151 & 0.073 & -1.10 \\
19.5 & 2.53 & 0.293 & 0.414 & 0.29 & 1.00 & 1.44 & 0.30 & 0.145 & 0.080 & -0.81 \\
20.0 & -4.99 & 0.343 & 0.449 & 0.24 & 1.19 & 1.54 & 0.23 & 0.108 & 0.102 & -0.05 \\
20.4 & -2.10 & 0.367 & 0.451 & 0.19 & 1.25 & 1.55 & 0.19 & 0.105 & 0.097 & -0.09 \\
21.2 & 4.15 & 0.326 & 0.444 & 0.27 & 1.18 & 1.52 & 0.22 & -0.024 & 0.082 & 1.30 \\
21.4 & -1.43 & 0.381 & 0.472 & 0.19 & 1.29 & 1.60 & 0.19 & 0.111 & 0.099 & -0.12 \\
24.0 & -0.83 & 0.450 & 0.531 & 0.15 & 1.46 & 1.74 & 0.16 & 0.073 & 0.106 & 0.31 \\
33.4 & 3.50 & 0.530 & 0.756 & 0.30 & 1.72 & 2.11 & 0.19 & 0.076 & 0.136 & 0.44 \\
35.6 & 3.11 & 0.628 & 0.818 & 0.23 & 1.90 & 2.19 & 0.13 & 0.092 & 0.142 & 0.35 \\
\hline
\end{tabular}

Table 2: Hydrodynamic coefficients in flume tank test reference (FT) for the Thyboron vf 15 model as a function of the hydrodynamic angles. And the corresponding aerodynamic coefficients in wind tunnels test reference (WT). $C_{D}, C_{L}$ and $C_{S}$ are the drag, lift and side force coefficients, $\alpha$ is the attack angle and $\beta$ is the side slip angle (degrees). Relative deviation from wind tunnel, $\varepsilon_{C_{D}}, \varepsilon_{C_{L}}$ and $\varepsilon_{C_{S}}$ are also shown. 


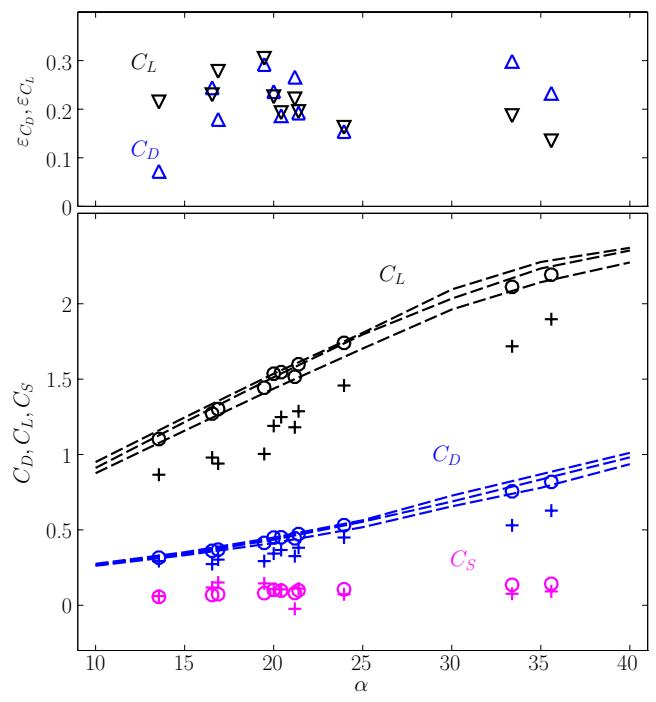

Figure 3: Hydrodynamic force coefficients (bottom panel) and deviation from wind tunnel tests (top panel) for the Thyboron vf 15 door. Plus signs denote flume tank results, while, circles indicate wind tunnel prediction for the same exact hydrodynamic angles. Dashed lines delimit wind tunnel prediction for $\beta=\{-5,0,5\}^{\circ}$. Deviations $\varepsilon$ are indicated with triangles. Black for $C_{L}$, blue for $C_{D}$ and magenta for $C_{S}$ (see labels).

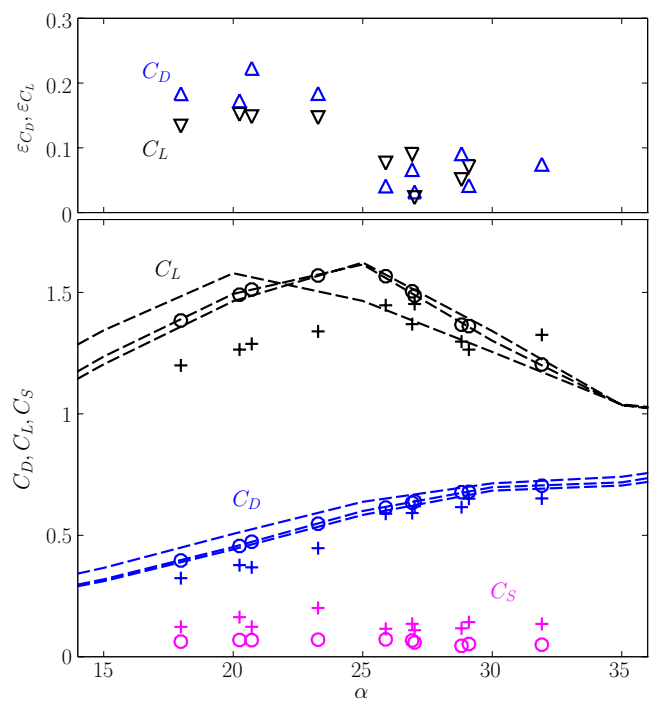

Figure 4: Hydrodynamic force coefficients (bottom panel) and deviation from wind tunnel tests (top panel) for the Grilli Fly door. Symbols and colours as in fig. 3 . 


\begin{tabular}{|cc|ccc|ccc|ccc|}
\cline { 3 - 11 } \multicolumn{1}{c|}{} & \multicolumn{4}{c|}{$C_{D}$} & \multicolumn{4}{c|}{$C_{L}$} & \multicolumn{3}{c|}{$C_{S}$} \\
\hline$\alpha$ & $\beta$ & $\mathrm{FT}$ & $\mathrm{WT}$ & $\varepsilon_{C_{D}}$ & $\mathrm{FT}$ & $\mathrm{WT}$ & $\varepsilon_{C_{L}}$ & $\mathrm{FT}$ & $\mathrm{WT}$ & $\varepsilon_{C_{S}}$ \\
\hline 18.0 & 0.89 & 0.324 & 0.396 & 0.18 & 1.20 & 1.38 & 0.13 & 0.123 & 0.0625 & -0.97 \\
20.2 & 1.55 & 0.377 & 0.456 & 0.17 & 1.26 & 1.49 & 0.15 & 0.163 & 0.0691 & -1.40 \\
20.7 & -0.04 & 0.368 & 0.474 & 0.22 & 1.29 & 1.51 & 0.15 & 0.123 & 0.0684 & -0.79 \\
23.3 & 0.59 & 0.447 & 0.548 & 0.18 & 1.34 & 1.57 & 0.15 & 0.201 & 0.0703 & -1.80 \\
25.9 & 1.14 & 0.589 & 0.614 & 0.04 & 1.45 & 1.57 & 0.08 & 0.115 & 0.0716 & -0.60 \\
26.9 & 1.20 & 0.592 & 0.634 & 0.07 & 1.37 & 1.50 & 0.09 & 0.136 & 0.0670 & -1.00 \\
27.0 & -0.28 & 0.620 & 0.640 & 0.03 & 1.45 & 1.49 & 0.02 & 0.109 & 0.0589 & -0.85 \\
28.8 & -0.90 & 0.616 & 0.678 & 0.09 & 1.30 & 1.37 & 0.05 & 0.117 & 0.0451 & -1.59 \\
29.1 & 0.45 & 0.651 & 0.679 & 0.04 & 1.26 & 1.36 & 0.07 & 0.143 & 0.0526 & -1.70 \\
31.9 & 0.46 & 0.652 & 0.704 & 0.08 & 1.33 & 1.20 & -0.10 & 0.135 & 0.0497 & -1.70 \\
\hline
\end{tabular}

Table 3: Same as in table 2 but for the Grilli Fly model. 